\title{
The effect of group spiritual care on hope in patients with multiple sclerosis referred to the MS Society of Zahedan, Iran
}

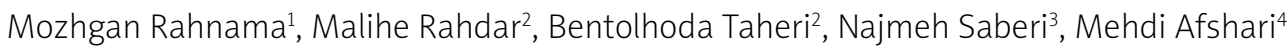 \\ ${ }^{1}$ Department of Nursing, Zabol University of Medical Sciences, Zabol, Iran \\ ${ }^{2}$ Community Nursing Research Center, Zahedan University of Medical Sciences, Zahedan, Iran \\ ${ }^{3}$ Department of Internal Surgery Nursing, Zahedan University of Medical Sciences, Zahedan, Iran \\ ${ }^{4}$ Department of Community Medicine, School of Medicine, Zabol University of Medical Sciences, Zabol, Iran \\ Neuropsychiatria i Neuropsychologia 2021; 16, 3-4: 161-167
}

Address for correspondence:

Dr Malihe Rahdar

Community Nursing Research Center

Zahedan University of Medical Sciences

Zahedan, Iran

e-mail: m.rahdar@zaums.ac.ir

\section{Abstract}

Introduction: Multiple sclerosis (MS) is known as an autoimmune disease and a chronic inflammatory condition, inducing a wide variety of mood affective disorders, including depression and feelings of hopelessness in many aspects of patients' quality of life (QoL). In view of the positive side effects of spirituality and spiritual care on finding appropriate strategies for further adaptation, this study aimed to determine the impact of group spiritual care (GSC) on levels of hope in patients suffering from MS.

Material and methods: This clinical trial was conducted on a total of 96 patients with MS, referring to the $\mathrm{Na}$ tional Multiple Sclerosis Society (NMSS) in the city of Zahedan, Iran. The data collection tools for this purpose included a demographic information form and the Adult Hope Scale completed by the subjects at the pre- and post-intervention stages. Additionally, the intervention group received five sessions of GSC during three weeks but the control group members only talked over daily issues along with their mental health problems.

Results: The Kruskal-Wallis test results revealed that the GSC intervention could have a significant positive effect on raising hope in the patients with MS $(p<0.001)$. Moreover, a significant increase was observed in the scores of hope dimensions including agency and pathway $(p<0.001)$.

Conclusions: GSC can effectively boost levels of hope in patients suffering from MS in all dimensions. Therefore, it is recommended to utilize this type of care in order to nurture hope in such individuals.

Key words: group spiritual care, hope, multiple sclerosis.

\section{Introduction}

Multiple sclerosis (MS) is known as a progressive and degenerative disease of the myelin sheath of the nerve cells in the central nervous system (CNS) (Givi and Hosseini Kiasari 2014), whose complications typically occur in individuals aged between 20 and 40 (Hosseini et al. 2013). Women also suffer from this condition two to three times more than men (Borghi et al. 2013). According to the statistics, approximately 2.5 million people live with MS worldwide (Damal et al. 2013); however, there are no accurate statistics on the number of cases in Iran. As reported at the Seventh International MS Congress in Iran, the number of patients with this condition was approximately 40 thousand (namely, 15 cases per 100 thousand people) (AshkTorab et al. 2011).
With reference to various studies in this field, the prevalence rate of cognitive and mental health disorders in patients with MS has been estimated at $30 \%$ to $70 \%$. Depression and feelings of hopelessness are among the common problems of chronic inflammatory diseases including MS (Givi and Hosseini Kiasari 2014). From this perspective, hopelessness accompanied by depression, death drive, and suicide attempts, has been defined as tolerance of insuperable conditions and situations, wherein it is not expected to achieve some goals (Baljani et al. 2011). In contrast, hope has been depicted as the process of thinking about personal goals as well as motivation and ways to accomplish them (Poorgholami et al. 2016). According to Snyder's Hope Theory and its related therapies, hope has been described as a construct consisting of two concepts: "agency", meaning the 
capacity to identify routes to personal goals and to start moving towards them, and "pathway", which refers to one's problem-solving ability to overcome existing obstacles in the routes to meet goals (Hirsch and Sirois 2016). For that reason, there is a significant positive relationship between hope and spirituality (Fallah et al. 2011). In this respect, spirituality and spiritual beliefs empower individuals to manage daily life stressors and aid them to feel peace, hope, and comfort and find faith (Frouzandeh et al. 2015). Connecting to the omnipotence also assures these individuals that a strong power will always care for them. These people feel more comfortable at events due to their faith and beliefs, they get less stressed and anxious, and as a result, their expectations for the future are much more optimistic (Salimi et al. 2017). In the course of crises and illnesses, spirituality similarly turns out to be of utmost importance. In fact, spiritual needs become more obvious, providing an opportunity for the delivery of spiritual care by nurses (Pahlevanzade et al. 2016).

Since nursing is intended to maintain and upgrade health, to prevent illnesses, and to relieve patient discomfort, spiritual care can have an important role in attaining this goal (Saeedi Taheri et al. 2013). Nurses' behavioral patterns in the field of spiritual care can be further divided into two categories: religious and non-religious interventions. In this regard, the religious interventions reflect on treating patients without bias through religious beliefs to endow them with opportunities to communicate with God and to express their values and beliefs and even to help them practice rituals via their referrals to religious leaders. On the other hand, non-religious interventions involve nurses showing love and compassion to patients at the bedside and next to family members, with direct eye contact and listening to their talk (Zehtab and Adib Hajbaghery 2014). Spiritual or religious care, which is assumed to be ethical, human-oriented, and sensitive to patients, is thus a valued part of overall care services (BolHari et al. 2012) that can aid patients find strategies for effective adaptation (Rahimi et al. 2013) because support for individuals with suffering and pain is the key aspect of this type of care (McSherry and Jamieson 2013).

Given the rising prevalence rate of MS in Iran and the little research on the effect of group spiritual care (GSC) on raising hope in patients with this condition, the present study aimed to determine the effect of GSC on levels of hope in patients with MS referring to the National
Multiple Sclerosis Society (NMSS) in the city of Zahedan, Iran.

\section{Material and methods}

This clinical trial was conducted on two groups, i.e., intervention and control, wherein the effect of GSC as the independent variable on hope was investigated in patients with MS referring to the NMSS in the city of Zahedan, Iran. Upon obtaining the letter of permission from the Ethics Committee of Zabol University of Medical Sciences (ZUMS), Zabol, Iran, and coordinating with the authorities, this study was completed over a period of three weeks. The study population included all of the patients with MS referring to the NMSS in the city of Zahedan, Iran, meeting the inclusion criteria, i.e., diagnosed with MS, no communication problems (namely, no hearing or vision impairment), reading and writing ability, a minimum age of 18 years, and adhering to Shia Islam. Among the exclusion criteria were the patients' unwillingness to cooperate at any stage of the study, need for intensive care services, immigration, and death. The data collection tools in this study were: 1) a demographic information form, validated by reviewing books and research articles as well as consulting with 10 faculty members at ZUMS, Zabol, Iran, whose reliability was measured using the test-retest method (this questionnaire comprised nine items related to demographic characteristics: age, disease duration, gender, marital status, number of children, level of education, insurance status, employment status, and family history of MS); and 2) the 12-item Adult Hope Scale (AHS) developed by Snyder et al. (2007) to assess levels of hope, administered as a self-assessment tool. The given questionnaire contained two dimensions, namely, agency (items no. 2, 9, 10, and 12) and pathway (items no. 1 , 4,6 , and 8). The misleading cases were items no. 3, 5, 7, and 11 (Zahed-Babelan et al. 2012). The scoring procedure in this questionnaire was based on a four-point Likert-type scale (definitely false $=$ 1 , relatively false $=2$, relatively true $=3$, definitely true $=4)($ Zahed-Babelan et al. 2012) and that was in reverse order for the items no. 3, 5, 7, and 11 (definitely false $=4$, relatively false $=3$, relatively true $=2$, definitely true $=1$ ). The scores of the misleading items were not included. The minimum and maximum possible scores obtained from the questionnaire were 8 and 32 , respectively. Accordingly, lower scores indicated low levels of hope and high scores represented high levels (Nasiri and Jowkar 2010). 
Snyder and Lopez in 2007 also reported the reliability coefficient of this scale as 0.80 , using the test-retest method, and its internal consistency through Cronbach's $\alpha$ from 0.74 to 0.84 (Khaledian and Sohrabi 2014). Nasiri and Jowkar in 2010 had similarly calculated the reliability of this scale via factor analysis and principal component analysis (PCA) with varimax rotation. The Kaiser-Meyer-Olkin (KMO) measure for this scale was equal to 0.81 and Bartlett's test of sphericity coefficient was 644.81, which was significant at the level of 0.0001 . Also, the results of the factor analysis showed two main factors on the scale, together explaining the variance as 0.51 . Cronbach's $\alpha$ was further employed to assess the reliability of this scale, wherein the coefficients of 0.62 and 0.74 were obtained for the sub-scales (Nasiri and Jowkar 2010). Kermani et al. in a study in 2010 on 371 graduate students from six universities based in the city of Tehran, Iran, also reported the convergent and divergent validity of the AHS compared with the Scale for Suicide Ideation (SSI, Beck $e t$ al. 1979: 0.535), the Multidimensional Scale of Perceived Social Support (MSPSS, Zimet et al. 1988: 0.407), and the Meaning in Life Questionnaire (MLQ, Steger et al. 2006: 0.575). The Cronbach's $\alpha$ reliability of this scale for agency, pathway, and in total was $0.77,0.79$, and 0.86, respectively (Kermani et al. 2011). In a study by Hamid (2011) recruiting a sample size of 364 students, Cronbach's $\alpha$ for the total scale was 0.89 and it was 0.71 and 0.67 for agency and pathway, respectively. This questionnaire also had internal consistency (Hamid 2011). The sample size in the present study was determined based on the results reported by Taghizadeh et al. (Taghizadeh and Mirallai 2011) at about $22 \%$ difference in changes in the resilience scores in two groups with and without interventions, by taking $20 \%$ attrition into account, using the Stata software (ver. 11), by about 48 people in each intervention and control group. The study samples, selected through the convenience sampling technique, meeting the inclusion criteria and signing oral and written informed consent forms, were accordingly randomized into two groups, i.e., intervention and control. To meet blinding in this study (namely, single-blind), both groups were separately invited and then the research purpose and methodology were explained. In the first phase of the study, the demographic information form and the AHS were distributed and then full explanations were given on how to complete them. In the second phase, the intervention, including GSC, was implemented. The intervention involved five group sessions for spiritual care, twice a week, lasting 45-60 minutes for a period of three weeks with three-day intervals between the sessions. The educational content of the intervention was developed based on some parameters within the spiritual strategies proposed by Richards and Bergin (1997) with orientations towards Islam, provided by an eligible religious expert (wearing religious clothes, completing seminary training, and having teaching experience). The topics presented in each session (Table 1) had already been employed in the study by Hosseini et al. (2013). Immediately after completion of the intervention, each patient was asked to recomplete the AHS.

During the implementation of GSC for the intervention group, five discussion sessions lasting 45-60 minutes were also held for the control group for a period of three weeks with three-day intervals regarding daily issues along with their mental health problems, wherein the patients could talk about their experiences of life and memories in this respect. As the final session ended, the AHS was also re-completed by the control group. They were ultimately appreciated and presented with educational packages. Furthermore, ethical considerations, including information confidentiality and right to withdraw at any stage of the study were respected.

The data were then analyzed using the SPSS Statistics software (ver. 14). To investigate the homogeneity of the groups in terms of the demographic characteristics, the chi-square test was exercised. To compare the group means and the effect of the spiritual care pattern developed by Richards and Bergin on levels of hope in patients with MS, the Wilcoxon signed-rank test and the Kruskal-Wallis test were respectively employed.

Table 1. Group spiritual care (GSC) and topics presented in each session

\begin{tabular}{ll} 
Sessions & Topics \\
First & $\begin{array}{l}\text { Introduction, briefing, and establishment } \\
\text { of group cohesiveness }\end{array}$ \\
\hline Second & $\begin{array}{l}\text { Role of the Holy Quran recitation in perso- } \\
\text { nal relaxation }\end{array}$ \\
\hline Third & $\begin{array}{l}\text { Role of recommended invocations and their } \\
\text { repetitions in personal relaxation }\end{array}$ \\
\hline Fourth & Role of daily prayers in personal relaxation \\
\hline Fifth & $\begin{array}{l}\text { Explanations for experiences of spiritual } \\
\text { care and its effects as well as preparation } \\
\text { of participants to leave groups and to use } \\
\text { their achievements }\end{array}$ \\
\hline
\end{tabular}




\section{Results}

The demographic information and the variables associated with the patients are presented in Tables 2 and 3, indicating that both groups were homogeneous in terms of the distribution of these variables.

Comparisons of hope scores among the patients in both study groups at the pre- and post-intervention stages are also provided in Table 4. Accordingly, no significant difference was observed in the median scores of hope in the intervention and control groups before the intervention with respect to the probability value obtained by the Kruskal-Wallis test $(p>0.001)$, but the results demonstrated a significant difference between the median scores of hope in both groups after the GSC intervention $(p<0.001)$. Similarly, the hope score in the control group showed no significant difference at the end of the study. The median score of hope in the control group thus decreased from 15 to 14.5 , which was not statistically significant $(p=0.785)$. Nevertheless, the median score increased from 15 to 22 in the intervention

Table 2. Comparison of mean and standard deviation of patients with multiple sclerosis in terms of individual characteristics (age, duration of disease) in the two groups before intervention

\begin{tabular}{|c|c|c|c|c|}
\hline \multirow{3}{*}{$\begin{array}{l}\text { Individual } \\
\text { characteristic }\end{array}$} & \multicolumn{2}{|c|}{ Group } & \multirow[t]{3}{*}{$P$-value } & \multirow[t]{3}{*}{ Test type } \\
\hline & Intervention & Control & & \\
\hline & Mean (SD) & Mean (SD) & & \\
\hline Age & $38.77(10.35)$ & $37.89(9.36)$ & 0.660 & \multirow{2}{*}{$\begin{array}{c}\text { Independent samples } \\
\text { t test }\end{array}$} \\
\hline Duration of disease & $14.50(9.18)$ & $12.08(7.80)$ & 0.229 & \\
\hline
\end{tabular}

Table 3. Comparison of frequency distribution of patients with multiple sclerosis in terms of demographic information in the two groups before intervention

\begin{tabular}{|c|c|c|c|c|c|c|}
\hline \multirow[t]{2}{*}{ Individual characteristic } & \multicolumn{2}{|c|}{ Intervention group } & \multicolumn{2}{|c|}{ Control group } & \multirow[t]{2}{*}{$P$ value } & \multirow{2}{*}{$\begin{array}{l}\text { Test } \\
\text { type }\end{array}$} \\
\hline & $n$ & $\%$ & $n$ & $\%$ & & \\
\hline \multicolumn{7}{|l|}{ Sex } \\
\hline Female & 43 & 89.58 & 43 & 89.58 & \multirow[t]{2}{*}{0.99} & \multirow[t]{2}{*}{$\chi^{2}$} \\
\hline Male & 5 & 10.42 & 5 & 10.42 & & \\
\hline \multicolumn{7}{|l|}{ Marital status } \\
\hline Single & 7 & 14.58 & 9 & 18.75 & \multirow[t]{3}{*}{0.346} & \multirow[t]{3}{*}{$\chi^{2}$} \\
\hline Married & 35 & 72.92 & 37 & 77.08 & & \\
\hline $\begin{array}{l}\text { Divorced } \\
\text { Widower }\end{array}$ & 6 & 12.5 & 2 & 4.17 & & \\
\hline \multicolumn{7}{|l|}{ Number of children } \\
\hline Less than 3 & 25 & 52.08 & 26 & 54.17 & \multirow[t]{2}{*}{0.838} & \multirow[t]{2}{*}{$\chi^{2}$} \\
\hline Three or more & 23 & 47.92 & 22 & 45.83 & & \\
\hline \multicolumn{7}{|l|}{ Education } \\
\hline Diploma or lower & 23 & 47.92 & 20 & 41.67 & \multirow[t]{2}{*}{0.538} & \multirow[t]{2}{*}{$\chi^{2}$} \\
\hline Higher than diploma & 25 & 52.08 & 28 & 58.33 & & \\
\hline \multicolumn{7}{|l|}{ Employment status } \\
\hline Employed & 17 & 35.42 & 14 & 29.17 & \multirow[t]{3}{*}{0.783} & \multirow[t]{3}{*}{$\chi^{2}$} \\
\hline Student & 2 & 4.17 & 3 & 6.25 & & \\
\hline Unemployed/retired & 29 & 60.42 & 31 & 64.58 & & \\
\hline \multicolumn{7}{|l|}{ Insurance status } \\
\hline Insured & 48 & 100 & 47 & 97.92 & \multirow[t]{2}{*}{0.500} & \multirow[t]{2}{*}{$\chi^{2}$} \\
\hline No insurance & 0 & 0 & 1 & 2.08 & & \\
\hline \multicolumn{7}{|c|}{$\begin{array}{l}\text { Other family members affec- } \\
\text { ted with multiple sclerosis }\end{array}$} \\
\hline Yes & 1 & 2.08 & 0 & 0 & \multirow[t]{2}{*}{ 0/99 } & \multirow[t]{2}{*}{$\chi^{2}$} \\
\hline No & 47 & 97.92 & 48 & 100 & & \\
\hline
\end{tabular}


group by $43 \%$, which was statistically significant $(p<0.001)$. The volume of changes in the intervention group was significantly higher than that in the control group $(p=0.0001)$.

Examining the percentage of changes in hope scores in different dimensions indicated a significant increase in all dimensions in the intervention group, including agency $(p<0.001)$ and pathway $(\phi<0.001)$ (Table 5).

\section{Discussion}

In the present study, the GSC intervention advocated hope in patients with MS. The findings also revealed that the patients with MS had low levels of hope before this intervention. Lack of complete recovery and exposure to recurrences may have thus caused them to experience feelings of hopelessness. According to Madani (2010), MS undermines a person's selfconfidence in the body health and, as recurrences are unpredictable, patients are induced to believe that they are unable to plan for their future (Madani et al. 2010). Mardanivalendani and Ghafari (2014) also believed that the prognosis of this disease was unknown and patients could be subjected to various types of physical, mental, social, and family-related disorders, severely affecting their independence in performance and planning for the future (Mardanivalendani and Ghafari 2014).
Moreover, the present study showed the positive effect of the Islam-based GSC on levels of hope in patients with MS. Accordingly, strengthening the spiritual beliefs in these patients during the intervention was possibly effective in achieving these results. As stated by Ghahremani and Nadi (2012), religious beliefs and faith in God would increase failure tolerance, prevent emergence of physical and mental illnesses, and ultimately raise hope for the future. Shoa Kazemi (2010), in a study investigating the relationship between religious adaptation strategies and mental health in patients with MS had correspondingly suggested that religiosity and religious practices could be regarded as effective strategies in terms of coping with stress and problems caused by this condition (Shoa Kazemi 2010). Additionally, Bussing et al. (2013) in their study on patients with MS had labeled faith as a factor giving sense to this disease, making patients view it as a chance to grow and gain value in life. In support of this, McNulty (2004) found that spiritual health could shape patient compliance with MS (McNulty et al. 2004); in particular, the appropriate level of mental health may not be evident in patients. According to Alahbakhshian et al. (2011), examining spiritual health in patients with MS, the majority of the patients $(97.9 \%)$ were at a moderate level in terms of spiritual health. So, they stressed the need to design programs to improve it with regard to the effects of this

Table 4. Comparison of hope scores in patients with multiple sclerosis between groups before and after intervention

\begin{tabular}{lccc} 
Hope & \multicolumn{2}{c}{ Group } & P-value \\
\cline { 2 - 3 } & Control group & Intervention group & \\
\cline { 2 - 3 } & $\begin{array}{c}\text { Middle } \\
\text { (distance between the percentiles) }\end{array}$ & $\begin{array}{c}\text { Middle } \\
\text { (distance between the percentiles) }\end{array}$ & 0.124 \\
\hline Before intervention & $15(11.5-18.5)$ & $15(14-18)$ & 0.0001 \\
\hline After intervention & $14.5(11-18.5)$ & $22(21-24)$ & 0.0001 \\
\hline Change percent & $0(-6.46 \& 8.01)$ & $43.30(29.41 \& 57.74)$ & \\
\hline
\end{tabular}

Table 5. Comparison of hope dimensions of patients with multiple sclerosis between groups before and after intervention

\begin{tabular}{|c|c|c|c|c|}
\hline \multirow[t]{3}{*}{ Hope } & \multicolumn{2}{|c|}{ Group } & \multirow[t]{3}{*}{$P$-value } & \multirow[t]{3}{*}{ Test type } \\
\hline & Intervention group & Control group & & \\
\hline & $\begin{array}{l}\text { Middle (distance between } \\
\text { the percentiles) }\end{array}$ & $\begin{array}{l}\text { Middle (distance between } \\
\text { the percentiles) }\end{array}$ & & \\
\hline \multicolumn{5}{|l|}{ Agent } \\
\hline Before intervention & $7(6 \& 9)$ & $7(6 \& 9.5)$ & 0.189 & Kruskal-Wallis \\
\hline After intervention & $11(10 \& 12)$ & $7(6 \& 8.5)$ & 0.0001 & Kruskal-Wallis \\
\hline \multicolumn{5}{|l|}{ Pathway } \\
\hline Before intervention & $8(7 \& 9)$ & $8(5 \& 10)$ & 0.847 & Kruskal-Wallis \\
\hline After intervention & $11(10 \& 13)$ & $8(6 \& 10)$ & 0.0001 & Kruskal-Wallis \\
\hline
\end{tabular}


factor on various aspects of patients' quality of life (QoL) (Allahbakhshian et al. 2011).

There were also research studies in which the impact of spirituality and hope was explored in patients suffering from other diseases, including the correlational study by Ottaviani et al. (2014), in which a direct positive relationship was found between levels of hope and sense of spirituality in patients with chronic renal failure (CRF) undergoing hemodialysis. Other studies, namely, the one by Salimi et al. (2017), reflected on the effect of group spiritual self-care on life expectancy in patients with coronary artery disease (CAD), the survey by Morassaie and Aghajani (2014), on the impact of spiritual-based counseling on life expectancy in patients with CRF (Morassaie and Aghajani 2014), and the study by Shoaa Kazemi and Saadati (2010) on the effect of cognitivebehavioral therapy on reducing hopelessness in women with confirmed breast cancer (Shoaa Kazemi and Saadati 2010). Although these investigations were different in terms of the type of intervention and the sample size recruited, they were included in this study because they examined the impact of strengthening spirituality on hope. Abdollahzadeh (2015) also believed that patients whose spiritual aspects of their life had been strengthened could effectively adapt to their disease. Life meaningfulness in stressful conditions was further introduced as the heart of any preventive-educational interventions in this domain (Abdollahzadeh et al. 2015).

\section{Conclusions}

This study established that GSC with an Islamic approach during five sessions, lasting 45-60 minutes, for three weeks, could raise hope and resilience in patients with MS. Therefore, strengthening beliefs and spirituality in these individuals could make them adopt positive attitudes to the world, help them to accept unchangeable conditions and situations such as diseases, and give them hope to live a better life. Considering the religiosity in the Iranian society, paving the grounds for uncomplicated GSC interventions, it is recommended to utilize this type of care for patients with MS. Furthermore, it is suggested to carry out studies recruiting a larger sample size aiming to identify factors affecting levels of hope in these individuals.

\section{Acknowledgements}

This article was derived from a research project (graduate thesis) approved by Zabol University of Medical Sciences (ZUMS), Zabol, Iran, with the code of ZBMU.1.REC.1396.81, and funded by the Vice Chancellor's Office for Research at ZUMS, Zabol, Iran. The authors hereby extend their gratitude to the respected authorities of the School of Nursing and Midwifery at ZUMS, Zabol, Iran, the staff working in the National Multiple Sclerosis Society (NMSS) in the city of Zahedan, Iran, and all patients contributing to this study.

\section{Disclosure}

The authors declare no conflict of interest.

\section{References}

1. Abdollahzadeh MS, Farzi F, Pirooz A, et al. Comparing the effects of caudal block and infiltration of local anesthetic on postoperative pain control in children. J Guilan Univ Med Sci 2015; 98: 61-69.

2. Allahbakhshian M, Jafarpour M, Parvizi S. Spiritual wellbeing of patients with multiple sclerosis. Iran J Nurs Midwifery Res 2011; 16: 202-206.

3. AshkTorab T, Jadid Milani M, Abed Saiedi J, et al. The effect of peer support groups on promotion of physical health status of patients suffering from multiple sclerosis. JGBFNM 2011; 9: 1-10.

4. Baljani S, Khashabi J, Amanpour E, et al. Relationship between spiritual well-being, religion, and hope among patients with cancer: faculty of nursing and midwifery. Tehran University of Medical Sciences (Hayat) 2011; 17: 27-37.

5. Beck AT, Kovacs M, Weissman A. Assessment of suicidal intention: the Scale for Suicide Ideation. J Consult Clin Psychol 1979; 47: 343-352.

6. BolHari J, Naziryy GH, Zamaniyan S. The effectiveness of spiritual therapeutic therapy approach on depression, anxiety, and stress in women with breast cancer. J Soc Women 2012; 3: 87-117.

7. Borghi M, Cavallo M, Carletto S, et al. Presence and significant determinants of cognitive impairment in a large sample of patients with multiple sclerosis. PLoS One 2013; 8: 1-9.

8. Bussing A, Witrh AG, Humbroich K, et al. Faith as a resourse in patients with multiple sclerosis is association with a positive interpretation of illness and experience of gratitude/awe. Evid Based Complement Alternat Med 2013; 2013: 128575.

9. Damal D, Stoker E, Foley JF. Optimizing therapeutics in the management of patients with multiple sclerosis: a review of drug efficacy, dosing, and mechanisms of action. Biologics 2013; 7: 247-258.

10. Fallah R, Gholzari M, Dastani M, et al. The effectiveness of group-based spiritual intervention on promoting hope and mental health in women with breast cancer. Thought Behav Clin Psychol 2011; 5: 69-80.

11. Frouzandeh N, Aein F, Noorian C. Introducing a spiritual care training course and determining its effectiveness on nursing students self-efficacy in providing spiritual care for the patients. J Educ Health Promot 2015; 4: 34.

12. Ghahremani N, Nadi MA. Relationship between religious/spiritual components, mental health and hope for the future in hospital staff of Shiraz public hospitals. Iran J Nurs 2012; 25: 1-11. 
13. Givi HG, Hosseini Kiasari ST. The effectiveness of cognitive-existential group therapy on hopelessness in patients with multiple sclerosis. Sci Res I Shahed University 2014; 21: 1-11.

14. Hamid N. Relationship between psychological hardiness, life satisfaction and hope with academic performance of pre-university female students. J Appl Psychol 2011; 4: 101-116.

15. Hirsch JK, Sirois FM. Hope and fatigue in chronic illness: the role of perceived stress. J Health Psychol 2016; 21: 451-456.

16. Hosseini E, Habibi M, Basharpuor S. Effectiveness of self-control training on dimensions of quality of life in multiple sclerosis patients. J Res Behav Sci 2013; 10: 746-756.

17. Kermani Z, Khodapanahi MK, Heydari M. Psychometric features of hope Snyder's scale. Quart I Appl Psychol 2011; 5: 7-23.

18. Khaledian M, Sohrabi F. The effectiveness of group therapy on reducing depression and increasing hope in the elderly with nesting syndrome. Quart J Clin Psychol 2014; 4: 79-102.

19. Madani H, Navipour H, Roozbayani P, et al. Effects of selfcare program education of patients on complications of multiple sclerosis. J Birjand Univ Med Sci 2010; 15: 54-60.

20. Mardanivalendani M, Ghafari Z. The effectiveness of logotherapy on quality of life among MS patients in Shahrekord. Sci I Ilam Univ Med Sci 2014; 23: 47-56.

21. McNulty K, Livneh H, Wilson LM. Perceived uncertainly, spiritual well-being and psychosocial adaptation in individuals with multiple-sclerosis. Rehabil Psychol 2004; 49: 91-99.

22. McSherry $\mathrm{W}$, Jamieson $\mathrm{S}$. The qualitative findings from an online survey investigating nurses'perceptions of spirituality and spiritual care. J Clin Nurs 2013; 22: 3170-3182.

23. Morassaie F, Aghajani M. The effect of counseling with spirituality approach on hope in patients with chronic renal failure. Complement Med J Faculty Nurs Midwifery 2014; 4: 776-786.

24. Nasiri H, Jowkar B. Significance of life, hope, life satisfaction and mental health in women. Womens Res 2010; 6: 157-176.

25. Ottaviani AC, Souza EN, Camargo Drago N, et al. Hope and spirituality among patients with chronic kidney disease undergoing hemodialysis: a correlational study. Rev Lat Am Enfermagem 2014; 22: 248-254.

26. Pahlevanzade M, Rahmani Nia F, Shabani R, et al. Comparing the effectiveness of pilates and resistance training exercises and their combination (pilates and resistance) on quality of life, muscular strength and fatigue in women with multiple sclerosis. Journal of Zanjan University of Medical Sciences \& Health Services 2016; 24: 1-15.

27. Poorgholami F, Abdollahifard S, Zamani M, et al. The effect of stress management training on hope in hemodialysis patients. Glob J Health Sci 2016; 8: 165-171.

28. Rahimi N, Nouhi E, Nakhaee N. Spiritual well-being and attitude toward spirituality and spiritual care in nursing and midwifery students. Iran J Nurs 2013; 26: 55-65.

29. Richards PS, Bergin AE. A spiritual strategy for counseling and psychotherapy. American Psychological Association 1997.

30. Saeedi Taheri Z, Asadzandi M, Ebadi A. The effect of spiritual care based on GHALBE SALIM model on spiritual experience in patients with coronary artery disease. Iran J Psychiatr Nurs 2013; 1: 45-53.

31. Salimi T, Tavangar H, Shokripour S, et al. The effect of spiritual self-care group therapy on life expectancy in pa- tients with coronary artery disease: an educational trial. J Rafsanjan Univ Med Sci 2017; 15: 917-928.

32. Shoaa Kazemi M. The relationship between religious coping strategies and mental health in MS patients. Proc Soc Behav Sci 2010; 5: 1387-1389.

33. Shoaa Kazemi M, Saadati M. The study of effective logo therapy on reduction hopelessness in breast cancer womem s in Tehran city. Iran J Breast Cancer 2010; 3: 40-48.

34. Snyder CR, Harris C, Anderson JR, et al. Adult Hope Scale (AHS). J Pers Soc Psychol 2007; 60: 570-585.

35. Steger MF, Frazier P, Oishi S, Kaler M, The meaning in life questionnaire: assessing the presence of and search for meaning in life. J Couns Psychol 2006; 53: 80.

36. Taghizadeh ME, Mirallai MS. Study of spiritual group therapy on increase of resiliency in female multiple sclerosis in Esfahan. Quart Health Psychol J 2011; 2: 82-102.

37. Zahed-Babelan A, Rezaei Jamaloei H, Herfati Sobhani R. an investigation of the relationship between attachment to God and resilience with meaningful life among students. Knowl Res Appl Psychol 2012; 13: 75-85.

38. Zehtab S, Adib Hajbaghery M. The importance of spiritual care in nursing. Nurs Midwifery Stud 2014; 3: 2.

39. Zimet GD, Dahlem NW, Zimet SG, Farley GK. The multidimensional scale of perceived social support. J Pers Assess 1988; 52: 30-41. 